\title{
Tecnologia da Informação Aplicada a Gerenciamento de Acervo Documental Histórico
}

\author{
Kayo Delgado Medeiros de Almeida ${ }^{1}$, Elon Gomes Vieira ${ }^{2}$, Carlos Vitor de Alencar \\ Carvalho $^{3}$, Magno Fonseca Borges ${ }^{4}$, José Jorge Siqueira ${ }^{5}$, Antônio de Paula \\ Pedrosa $^{6}$, Douglas Moreno Moreira ${ }^{8}$, Bruno M. Lemos ${ }^{7}$ \\ ${ }^{1}$ Universidade Severino Sombra, Centro de Ciências Exatas e Tecnológicas \\ e da Natureza, Sistemas de Informação, kayodelgado@gmail.com \\ ${ }^{2}$ Universidade Severino Sombra, Centro de Ciências Exatas e Tecnológicas \\ e da Natureza, Sistemas de Informação, elongvieira@yahoo.com.br \\ ${ }^{3}$ Universidade Severino Sombra, Centro de Ciências Exatas e Tecnológicas \\ e da Natureza, Curso de Sistemas de Informação e Programa de Mestrado \\ Profissional em Educação Matemática e UnifOA - Centro Universitário de \\ Volta Redonda - Departamento das Ciências de Tecnologia e Engenharias, \\ cvitorcegmail.com \\ ${ }^{4}$ Universidade Severino Sombra, Centro de Documentação Histórica, \\ cdh@uss.br \\ ${ }^{5}$ Universidade Severino Sombra, Curso de História e Programa de Mestrado \\ em História, jjsiqueira@globo.com \\ ${ }^{6}$ Universidade Severino Sombra, Centro de Ciências Exatas e Tecnológicas \\ e da Natureza, Sistemas de Informação, tonywebdevelop@hotmail.com \\ ${ }^{7}$ Universidade Severino Sombra, Centro de Ciências Exatas e Tecnológicas \\ e da Natureza, Sistemas de Informação, douglasmorenomoreira@gmail.com \\ ${ }^{8}$ Universidade Severino Sombra, Centro de Ciências Exatas e Tecnológicas \\ e da Natureza, Sistemas de Informação, bruno.mathematic@gmail.com
}

Resumo: Este artigo mostra a aplicação de Tecnologia da Informação juntamente com conceitos de GED no Centro de Documentação Histórica da Universidade Severino Sombra. Um sistema desenvolvido em plataforma livre, em funcionamento, com finalidade de disponibilizar imagens digitais de acervos históricos sob guarda do Centro de Documentação Histórica. Esta solução foi proposta por um projeto de preservação de todo acervo documental histórico apoiado pela Fundação de Amparo a Pesquisa do Estado do Rio de Janeiro - FAPERJ, com isso o sistema tem por excelência a disponibilização das imagens, cadastro e consulta dos documentos, gerenciamento de desarquivamento, uso e desarquivamento de documentos, cadastro e gerenciamento de usuários com privilégios para cada tipo, registro de ações e histórico de pesquisa por cada usuário e entre outros. Com esta solução é possível disponibilizar um acervo para ser pesquisado por vários usuários ao mesmo tempo e sem danificar o documento original, que estará sempre bem guardado e protegido. O artigo também apresenta uma visão geral das interfaces gráficas do sistema desenvolvimento.

\section{Introdução}

O Centro de Documentação Histórica (CDH) da Universidade Severino Sombra (USS) tem sob sua guarda um acervo documental histórico do século XVIII em diante no qual disponibiliza para consulta por historiadores e população interessada. Para tal disponibilização, o $\mathrm{CDH}$ tinha toda uma rotina manual que demandava um esforço humano muito alto para manter a ordem e qualidade. Um problema do $\mathrm{CDH}$ era o fato 


\section{Revista TECCEN - Edição Especial - volume 2 - número 1 - março de 2009 - ISSN 1984-0993}

da degradação natural, química e por utilização excessiva dos documentos. Com essa problemática surgiu o projeto de implantar um sistema para gerenciamento desses documentos e sua disponibilização digital. Não basta apenas informatizar, ou seja, passar rotinas manuais para rotinas computacionais. É necessário entender um pouco sobre alguns conceitos como GED (Gerenciamento Eletrônico de Documentos) e Tecnologia da Informação.

Gerenciamento eletrônico de documentos ou gestão eletrônica de documentos (GED) é uma tecnologia que provê um meio de facilmente gerar, controlar, armazenar, compartilhar e recuperar informações existentes em documentos. Documentos formam a grande massa de conhecimentos de uma empresa. O GED permite preservar esse patrimônio e organizar eletronicamente a documentação, para assegurar a informação necessária, na hora exata, para a pessoa certa. O GED lida com qualquer tipo de documentação. A Tecnologia da Informação (TI) pode ser definida como um conjunto de todas as atividades e soluções providas por recursos de computação [Wikipedial 2008 e Wilipedia2 2008].

Baseado nesses conceitos o sistema começou a ser desenvolvido, e hoje seu desenvolvimento utiliza tecnologia Java (JSDK 1.6) [Deitel 2002], IDE NetBeans 6.1/6.5 [Gonçalves 2008], servidor Apache TomCat, Adobe e Sistema Operacional Ubuntu LTS. Com as tecnologias acima, pode-se observar a escolha por Software Livre. Sua escolha foi devida, não somente a redução de custos para a instituição, mas mostrar que esta solução é viável e também possibilitar aos profissionais e acadêmicos ampliarem seus conhecimentos e experiências nesta área [Almeida 2008a].

O restante deste artigo está organizado da seguinte forma: na seção 2 são detalhados conceitos de desenvolvimento Desktop e desenvolvimento WEB; considerações sobre o sistema desenvolvimento são descrito na seção 3 . Na seção 4 apresentam-se as considerações finais.

\section{Desenvolvimento Desktop x Desenvolvimento $W E B$}

No início do projeto o sistema começou a se desenvolvido para desktop, sua primeira versão, apenas o visualizador de imagens, foi apresentado e ele tinha a capacidade de abrir imagens e navegar por cada página de cada acervo aplicando zoom entre outras funcionalidades básicas de visualização de imagem. (Figura 1 e Figura 2) [Almeida 2008b]. Somente a visualização não era necessária. Era importante ter um gerenciamento para as imagens digitais, cadastro de usuários, níveis de permissão, gerência de ações. Então com essas necessidades, o sistema foi repensado e refeito com desenvolvimento WEB. A elicitação do sistema foi feita em cima das necessidades do $\mathrm{CDH}$ e as decorrentes durante o projeto. A metodologia utilizada foi a XP onde a elicitação e feita junto com a programação e os resultados exibidos para melhorias e correção.

O desenvolvimento $W E B$ gerou outras necessidades. Retiramos a necessidade das máquinas clientes possuírem hardware com desempenho adequado para aplicação web em vez de única máquina potente o suficiente. Passamos toda a responsabilidade de processamento e segurança para uma única máquina potente o suficiente para isto. Foi possível aproveitar tecnologias prontas e gratuitas para incorporar ao sistema, como por exemplo, o Acrobat Reader da Adobe (pode ser um genérico que funcione com seu navegador) para fazer toda a parte de visualização com a qualidade dos arquivos PDF. 


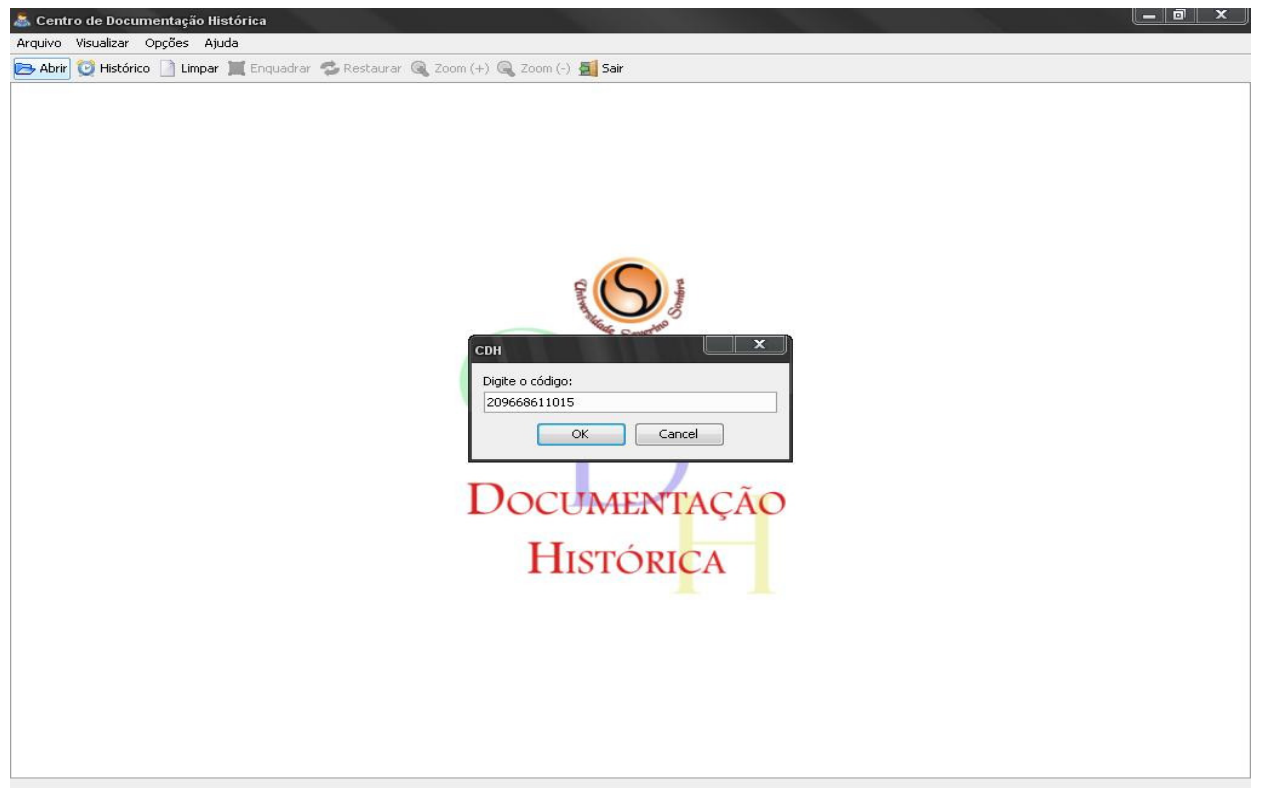

Figura 1. Abrindo imagem.

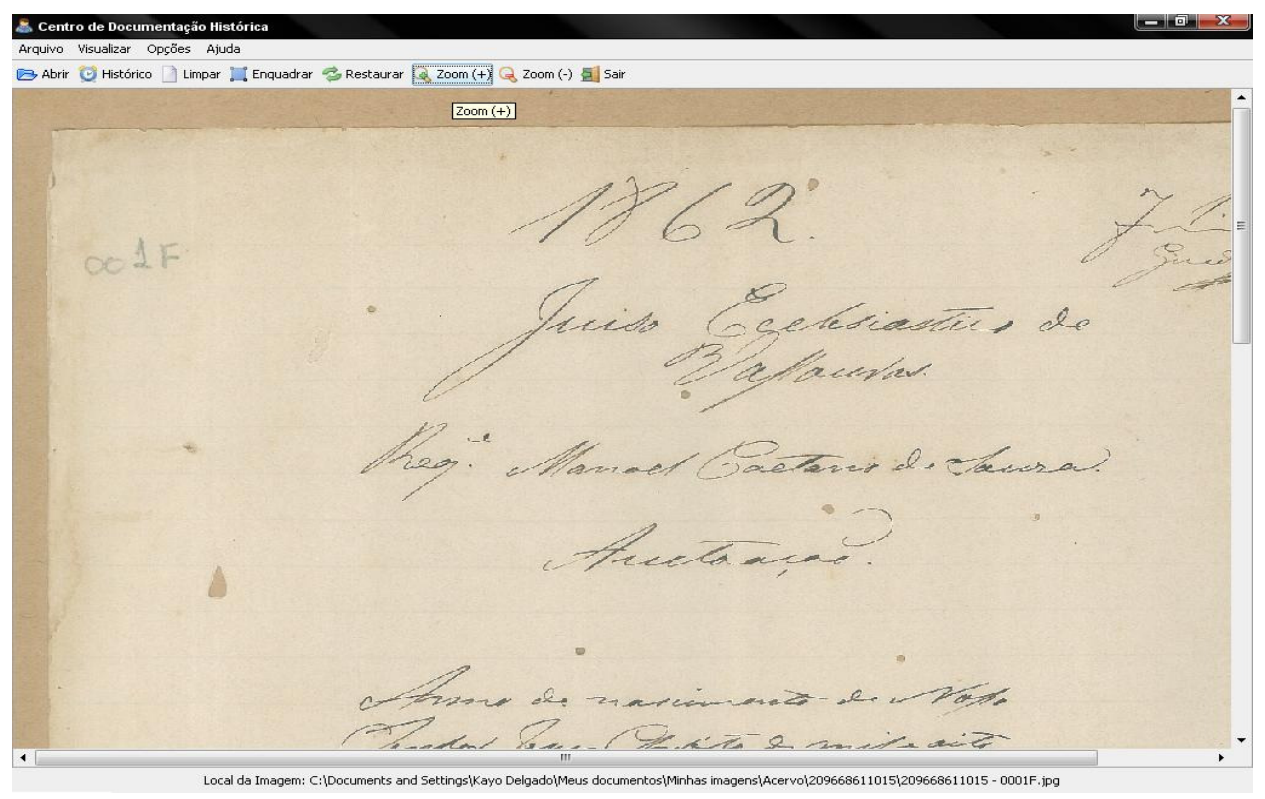

Figura 2. Visualização da imagem com zoom.

\section{O Sistema desenvolvido}

O sistema possui cadastro de usuários com nível de privilégios (Pesquisador e Administrador). O cadastro é efetuado pelo próprio usuário acessando a opção "cadastrar" na página inicial do sistema (Figura 3) e ele possui todo tratamento para campos obrigatórios e validação de CPF, portanto não terá como se cadastrar sem seu CPF. Então como disponibilizar o sistema para usuários que não possuem CPF? Simples, o funcionário, com seu nível de administrador, podem cadastrar qualquer usuário sem numero de CPF, portanto o sistema registra esta ação para prestação de contas em um possível problema acarretado por esta ação. (Figura 4). 
Revista TECCEN - Edição Especial - volume 2 - número 1 - março de 2009 ISSN 1984-0993

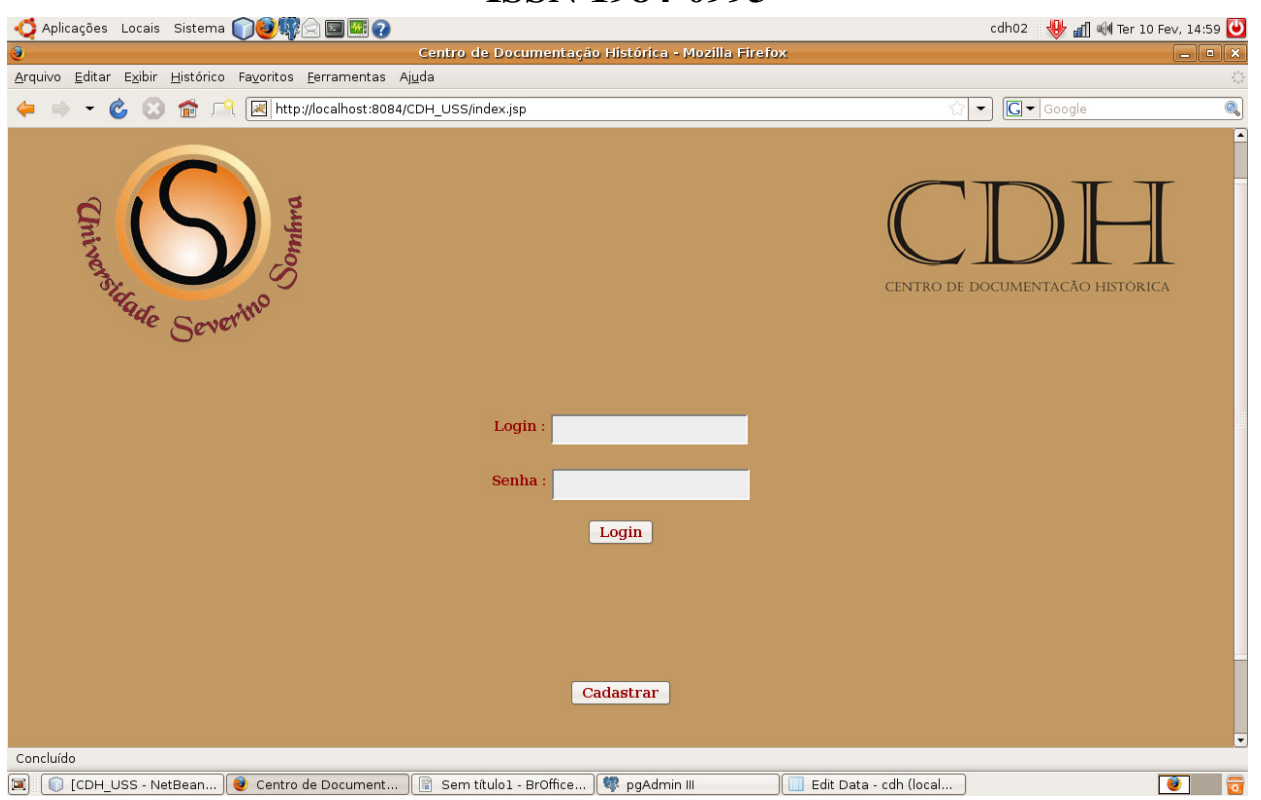

Figura 3 - Tela Inicial.

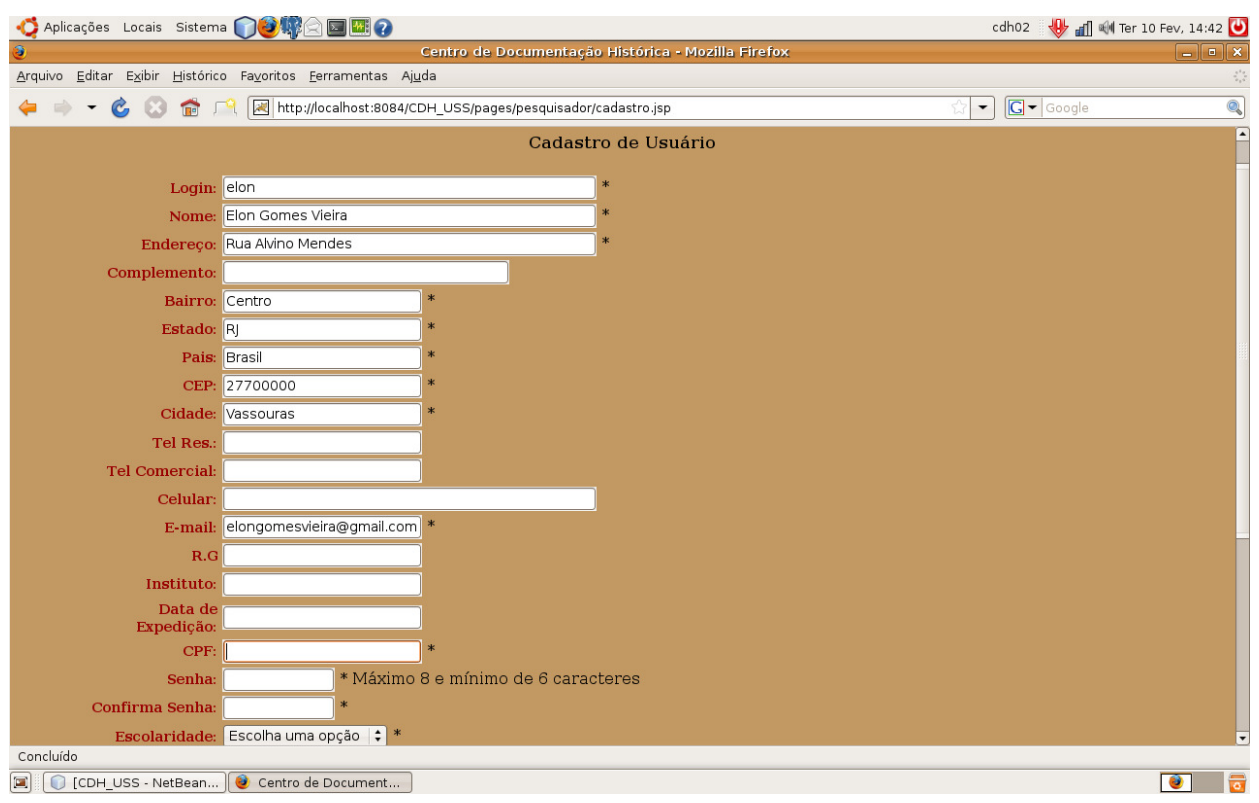

Figura 4 - Tela de Cadastro.

Com login pronto, o pesquisador pode logar e se tudo estiver correto ele é direcionado para uma página personalizada contendo um buscador para pesquisar os documentos e com menus de interação com o sistema como é mostrado na Figura 5. A seguir são mostrados alguns itens importantes do menu pesquisador: 
Revista TECCEN - Edição Especial - volume 2 - número 1 - março de 2009 ISSN 1984-0993

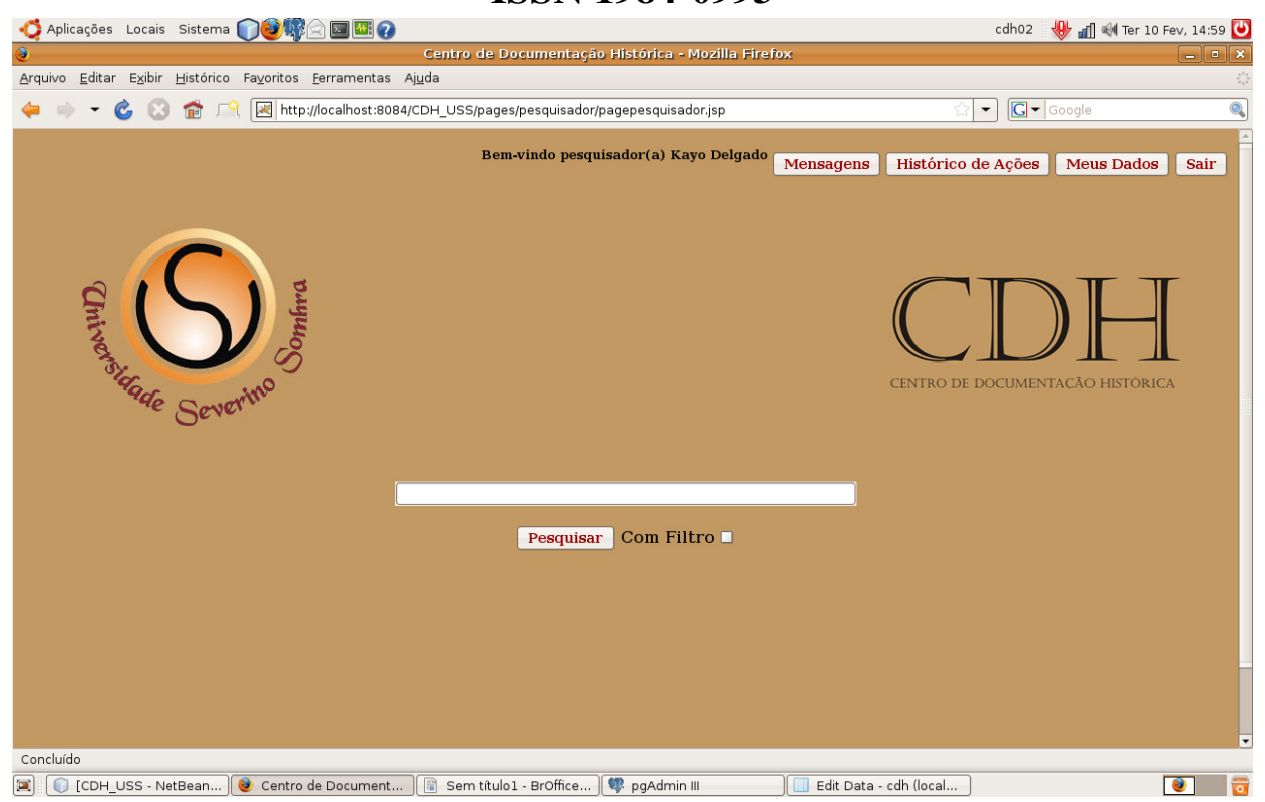

Figura 5 - Página Personalizada.

- Mensagem: mensagens que o sistema envia ao usuário para relatar algum problema com o processo de desarquivamento do documento solicitado (Figura 6).

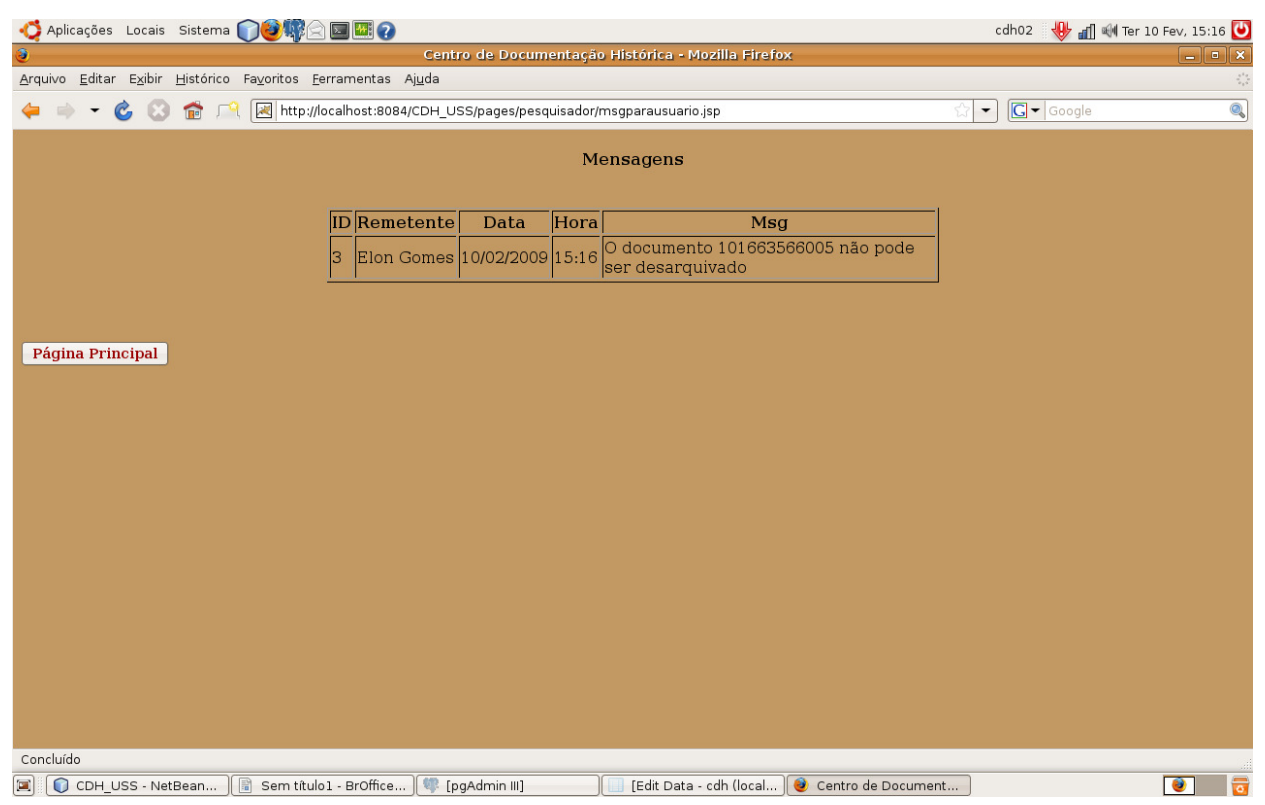

Figura 6 - Mensagem.

- Histórico: listagem de todas as ações de pesquisas efetuadas pelo pesquisador a fim de facilitar uma consulta a um documento que já tenha sido realizada (Figura 7). 


\section{Revista TECCEN - Edição Especial - volume 2 - número 1 - março de 2009 - ISSN 1984-0993}

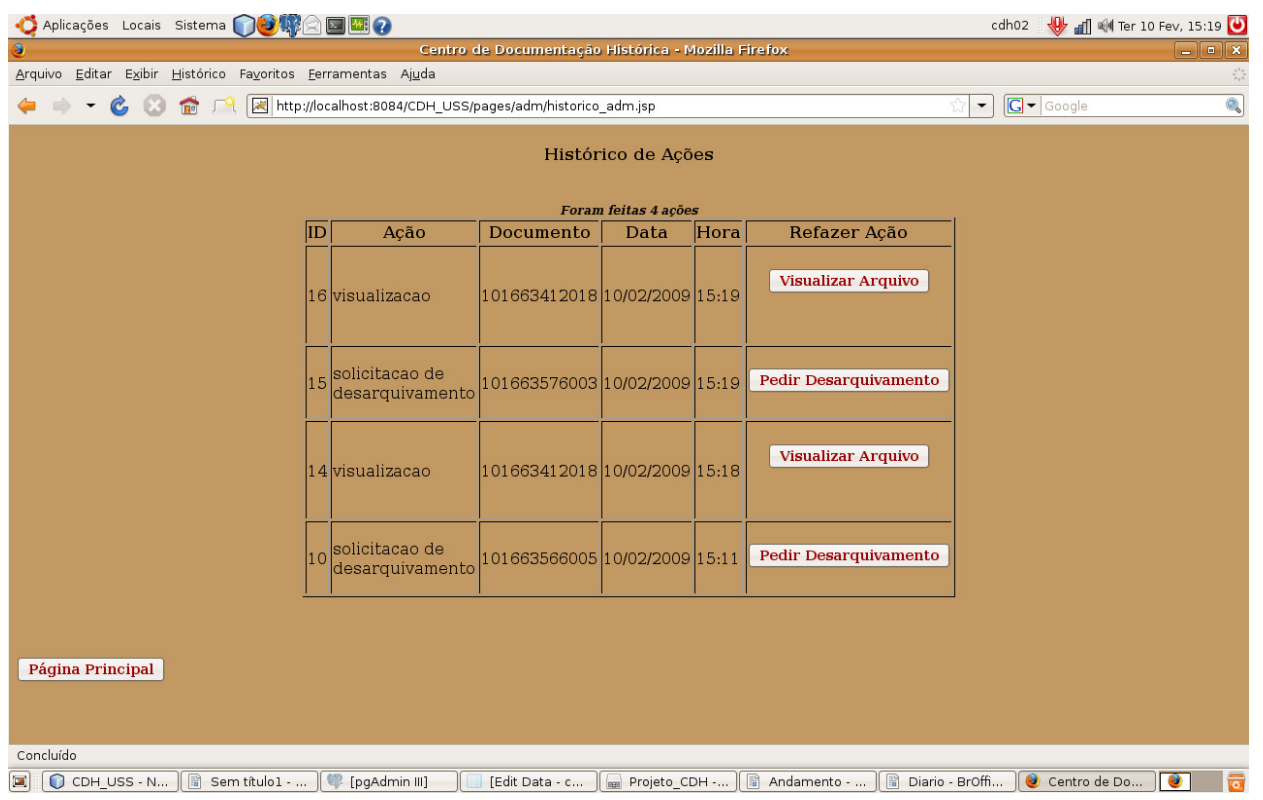

Figura 7 - Histórico das ações efetuadas.

- Meus Dados: página onde o pesquisador poderá atualizar seus dados e alterar sua senha no sistema (Figura 8).

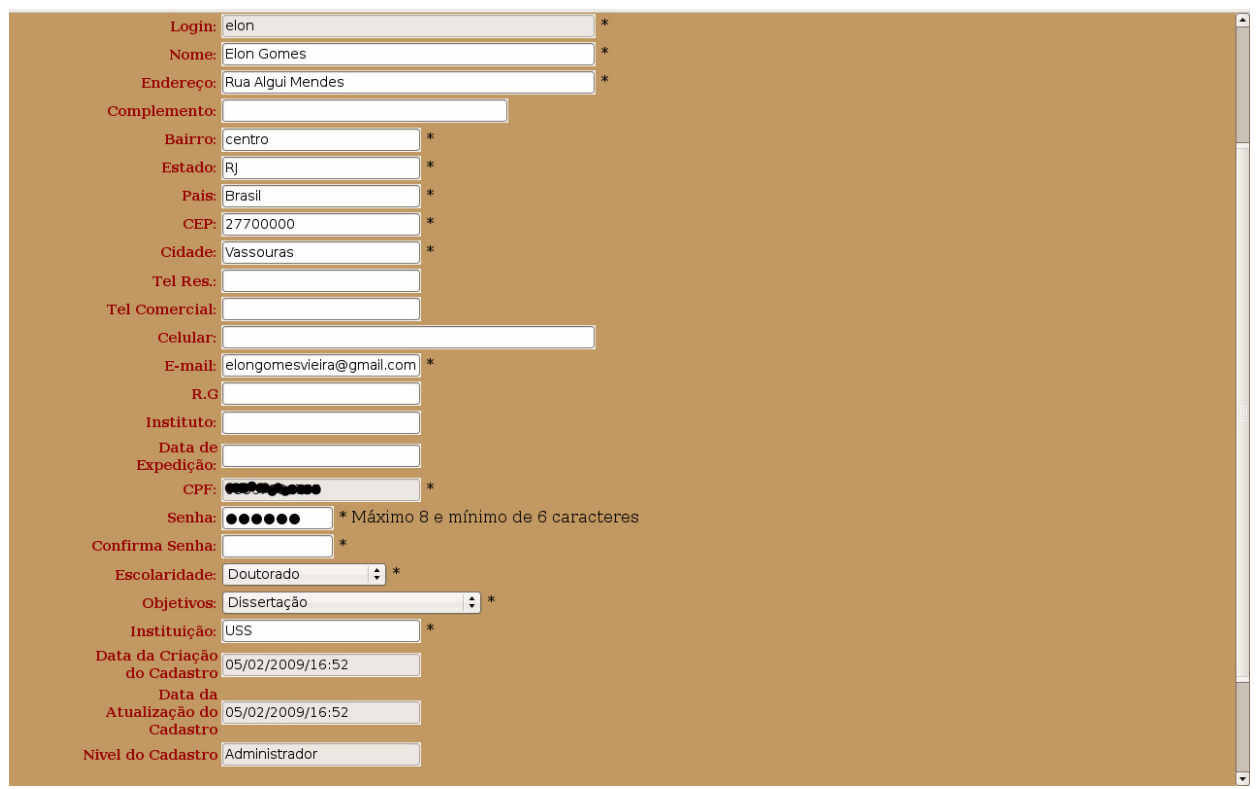

Figura 8 - Dados do pesquisador.

- Log Out: sair do sistema.

Quando um pesquisador efetua sua pesquisa os resultados são exibidos em uma lista de 100 em 100 resultados com indicadores de páginas navegáveis (Figura 9). As fases de digitalização e disponibilização do acervo ainda estão em desenvolvimento, portanto o sistema tem uma rotina inteligente que identifica se há ou não imagem digital a ser visualizada, caso sim o sistema exibe um botão visualizar (Figura 10) que arremete a uma página de visualização completa do acervo com navegação entre imagens (Figura $11)$.

Quando o acervo ainda está indisponível para visualização digital, um botão de solicitar desarquivamento é exibido (Figura 9), ao clicar neste botão o sistema envia uma solicitação de desarquivamento que é monitorada por um administrador em uma 


\section{Revista TECCEN - Edição Especial - volume 2 - número 1 - março de 2009 - ISSN 1984-0993}

tela específica, o administrador recebe sinal sonoro, reconhece o acervo, desarquiva-o fisicamente e no sistema e leva ao atendente para realizar a entrega. $O$ pesquisador pode apenas solicitar um documento por vez, ele só fica liberado para outra solicitação após a entrega do documento e a solicitação de arquivamento efetuada pelo atendente. Com esse processo um sinal sonoro diferente é acionado e o administrador responsável pelo acervo arquiva-o fisicamente e no sistema. Enquanto os acervos estão em mãos de pesquisadores, eles ficam em uma coluna de "EM USO" no sistema. (Figura 12).

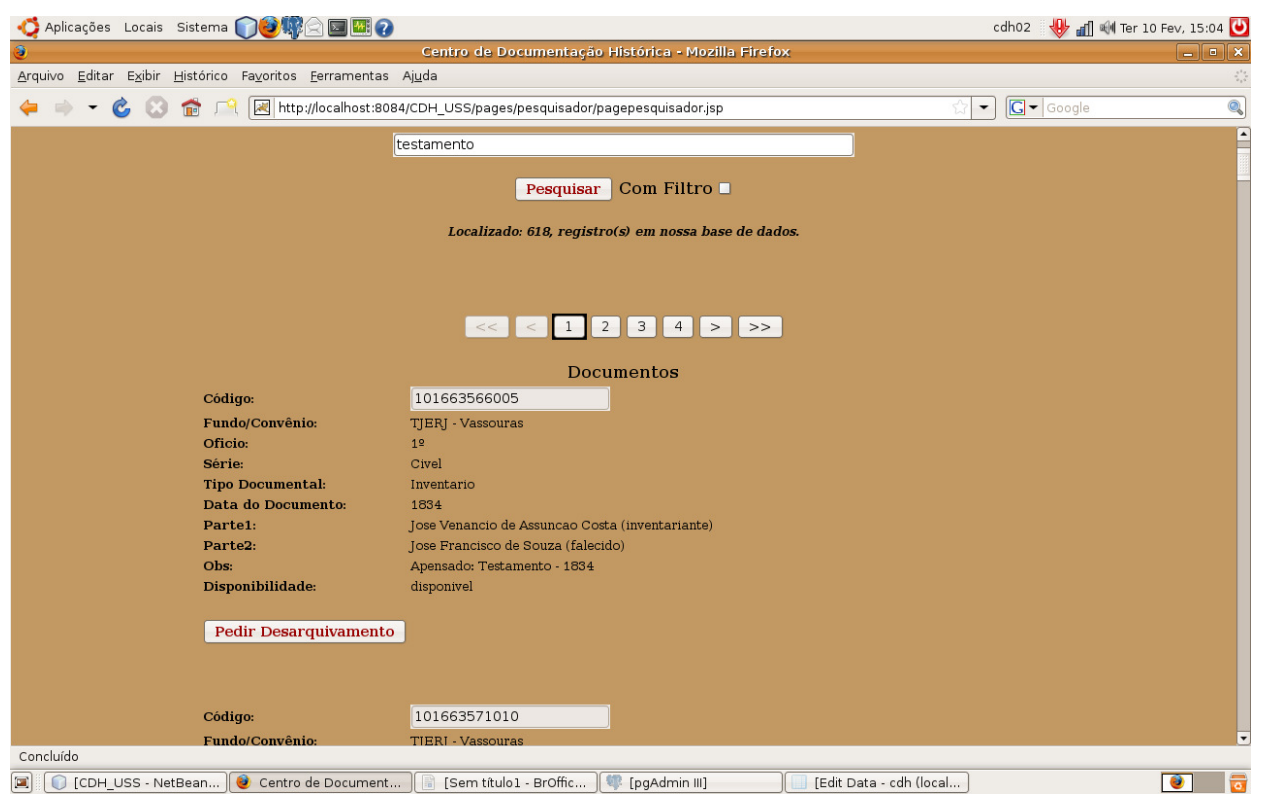

Figura 9 - resultados exibidos em uma lista de 100 em 100 resultados com indicadores de páginas navegáveis.

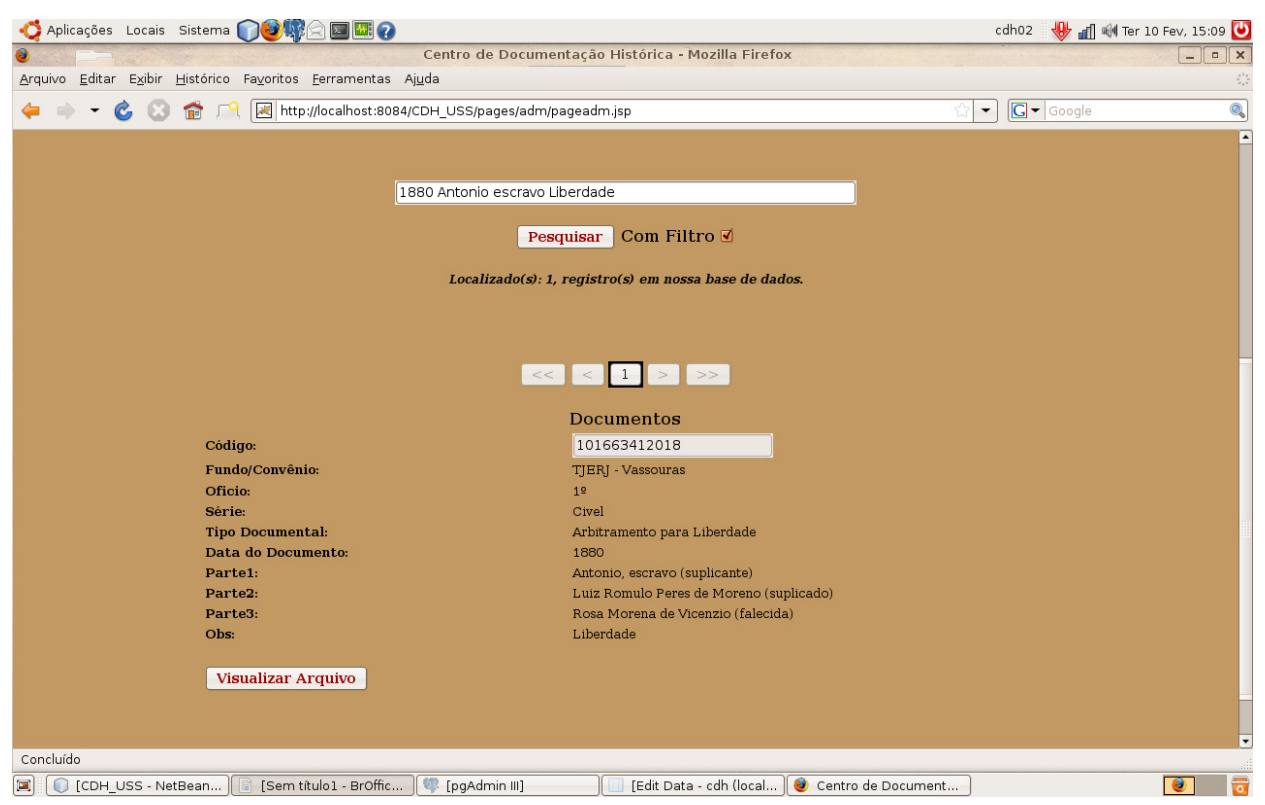

Figura 10 - 0 sistema tem uma rotina inteligente que identifica se há ou não imagem digital a ser visualizada, caso sim o sistema exibe um botão visualizar. 


\section{Revista TECCEN - Edição Especial - volume 2 - número 1 - março de 2009 - ISSN 1984-0993}

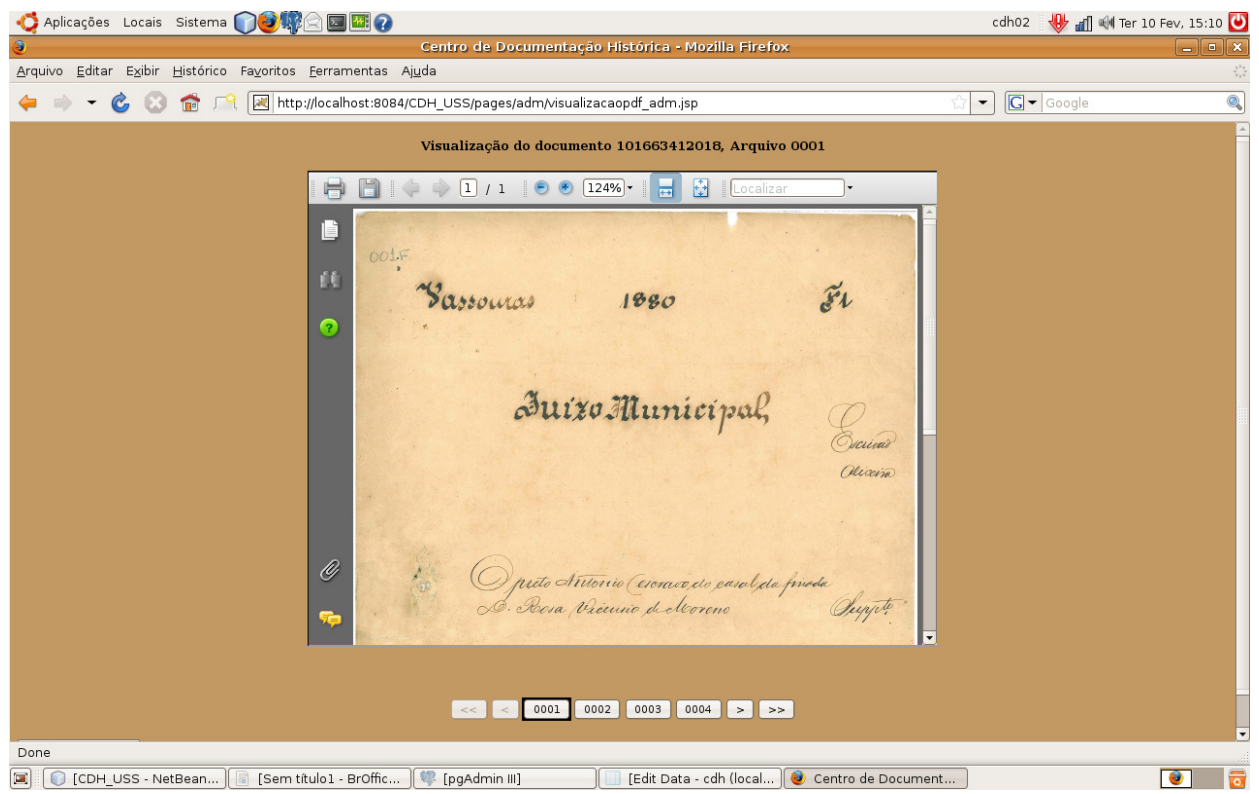

Figura 11 - visualização completa do acervo com navegação entre imagens.

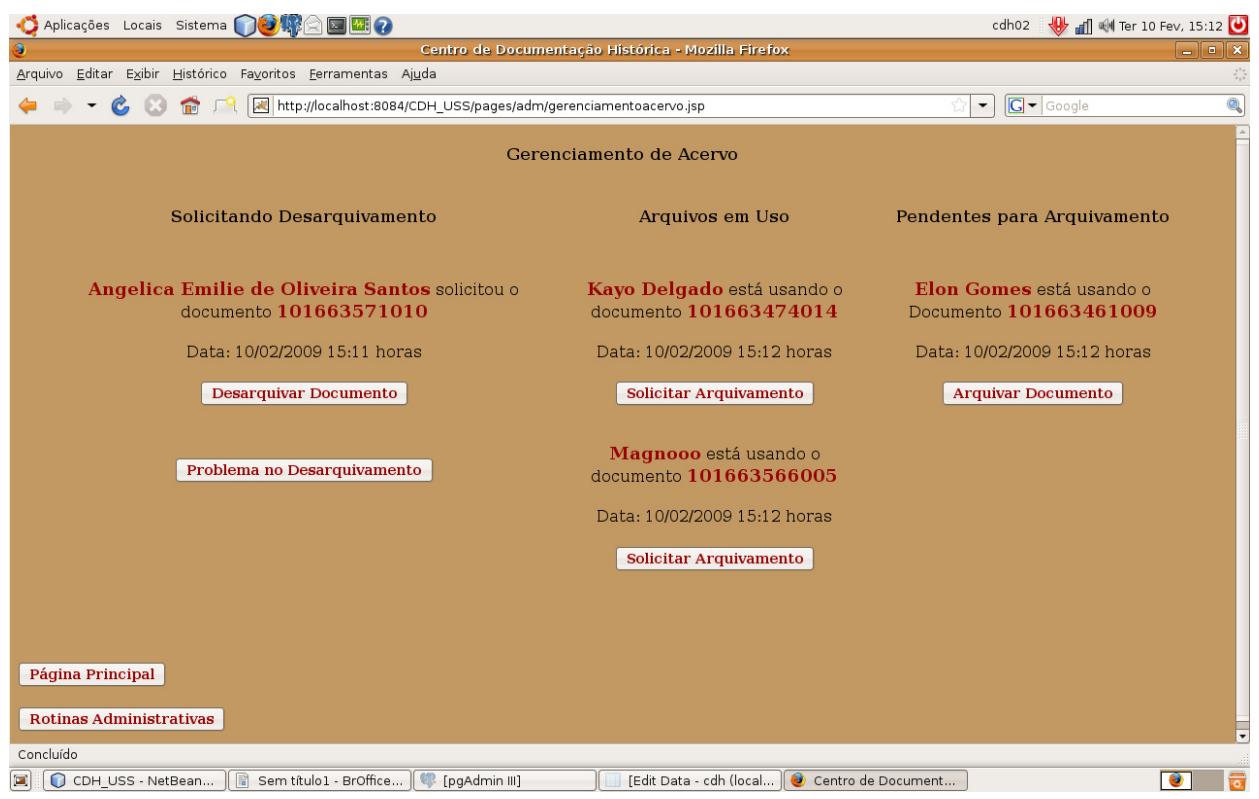

Figura 12 - Imagem mostrando que enquanto os acervos estão em mãos de pesquisadores, eles ficam em uma coluna de "EM USO" no sistema.

Com todos esses procedimentos descritos acima podemos notar que o sistema além de tratar dos arquivos digitais, também auxilia aos funcionários do $\mathrm{CDH}$ a monitorar e controlar o uso dos documentos históricos.

\section{Considerações Finais}

A aplicação da tecnologia da informação é de vasta amplitude e diversidade. Neste artigo podemos ver o quão proveitoso e de vital importância foi para a instituição a aderência e inclusão da TI em sua rotina. Com essas experiências podemos dizer que a interdisciplinaridade é a peça fundamental para o sucesso de cada aplicação.

Vale lembrar que o sistema está em constante evolução e vem sido todo estruturado em plataformas livres, felizmente isso significa que não acabamos por aqui e que outros poderão continuar a trajetórias já cursadas até aqui. Como futuras 


\section{Revista TECCEN - Edição Especial - volume 2 - número 1 - março de 2009 - ISSN 1984-0993}

implementações estão à disponibilização das imagens via internet e a consideração de código de barras para representar o código do acervo.

\section{Agradecimentos}

Os autores agradecem à FAPERJ (Fundação de Amparo à Pesquisa do Estado do Rio de Janeiro) pelo auxílio financeiro recebido. O primeiro autor agradece pela bolsa de Iniciação Científica recebida da FAPERJ. O terceiro autor agradece a FUNDADESP (Fundação Nacional de Desenvolvimento do Ensino Superior Particular) pela bolsa de produtividade de pesquisa de doutorado.

\section{Referências Bibliográficas}

Almeida, K. D. M ; Carvalho, C. V. A. ; Borges, M. F. ; Izzo, W. P.; Siqueira, J. J. (2008a) . Pesquisa e Desenvolvimento de uma ferramenta computacional para visualização de imagens digitais. In: I WorkShop de Informática Aplicada e Desenvolvimento de Jogos para Computatores e Dispositivos Móveis. ISBN: 9788588187030, 2008, Vassouras. 2008. v. 1. p. 1-4.

Almeida, K. D. M ; Junior, J. A. T. L ; Carvalho, C. V. A. (2008b). Total Cost of Ownership TCO: Uma Ferramenta Aplicável a todos os segmentos que utilizem TI: Estudo de caso do Centro de Documentação Histórica. In: VII Encontro de Iniciação Científica da USS, 2008, Vassouras. Fusve, 2008. v. 1. p. 1-1.

Cenadem (2008), http://www.cenadem.com.br/ged01.php, acessado em Janeiro de 2009.

Deitel H. M., Deitel P. J. (2002) Java Como Programar: 4ª edição. Bookman 2002.

Gonçalves, E. (2008) Desenvolvendo Aplicações Web com Netbeans IDE 6, Editora Ciência Moderna, 2008.

Wikipedia1 (2008), http://pt.wikipedia.org/wiki/GED, acessado em Janeiro de 2009.

Wikipedia2 (2008), http://pt.wikipedia.org/wiki/Tecnologia_da_informação, acessado em Janeiro de 2009. 